\title{
Higher blood pressure in normal weight women with PCOS compared to controls
}

\author{
Jan Roar Mellembakken (101,*, Azita Mahmoudan ${ }^{1, *}$, Lars Mørkrid², Inger Sundström-Poromaa ${ }^{3}$, \\ Laure Morin-Papunen ${ }^{4}$, Juha S Tapanainen ${ }^{4,5}$, Terhi T Piltonen (104) Angelica Lindén Hirschberg(1)6, \\ Elisabet Stener-Victorin ${ }^{7}$, Eszter Vanky ${ }^{8,9}$, Pernille Ravn ${ }^{10}$, Richard Christian Jensen ${ }^{11}$, \\ Marianne Skovsager Andersen ${ }^{11}$ and Dorte Glintborg ${ }^{11}$ \\ ${ }^{1}$ Division of Gynecology and Obstetrics, Department of Reproductive Medicine, Oslo University Hospital, Oslo, Norway \\ ${ }^{2}$ Department of Medical Biochemistry, Oslo University Hospital, Rikshospitalet, Oslo, Norway \\ ${ }^{3}$ Department of Women's and Children's Health, Uppsala University, Uppsala, Sweden \\ ${ }^{4}$ Department of Obstetrics and Gynecology, University Hospital of Oulu, University of Oulu, Medical Research Centre Oulu and PEDEGO Research Unit, \\ Oulu, Finland \\ ${ }^{5}$ Department of Obstetrics and Gynecology, Helsinki University Hospital and University of Helsinki, Helsinki, Uusimaa, Finland \\ ${ }^{6}$ Department of Women's and Children's Health, Karolinska Institutet and Department of Gynecology and Reproductive Medicine, Stockholm, Sweden \\ ${ }^{7}$ Department of Physiology and Pharmacology, Karolinska Institutet, Stockholm, Sweden \\ ${ }^{8}$ Department of Clinical and Molecular Medicine, Norwegian University of Science and Technology, Trondheim, UK \\ ${ }^{9}$ Department of Gynecology and Obstetrics, St. Olav's Hospital, Trondheim, Norway \\ ${ }^{10}$ Department of Gynecology and Obstetrics, Odense University Hospital, Odense, Denmark \\ ${ }^{11}$ Department of Endocrinology, Odense University Hospital, Odense, Denmark
}

Correspondence should be addressed to D Glintborg: dorte.glintborg@rsyd.dk

*(J R Mellembakken and A Mahmoudan contributed equally to this work)

\begin{abstract}
Objective: Obesity is considered to be the strongest predictive factor for cardio-metabolic risk in women with polycystic ovary syndrome (PCOS). The aim of the study was to compare blood pressure (BP) in normal weight women with PCOS and controls matched for age and BMI.

Methods: From a Nordic cross-sectional base of 2615 individuals of Nordic ethnicity, we studied a sub cohort of 793 normal weight women with BMI $<25 \mathrm{~kg} / \mathrm{m}^{2}$ (512 women with PCOS according to Rotterdam criteria and 281 age and BMI-matched controls). Participants underwent measurement of BP and body composition (BMI, waist-hip ratio), lipid status, and fasting BG. Data were presented as median (quartiles). Results: The median age for women with PCOS were $28(25,32)$ years and median BMI was $22.2(20.7,23.4) \mathrm{kg} / \mathrm{m}^{2}$. Systolic BP was $118(109,128) \mathrm{mmHg}$ in women with PCOS compared to $110(105,120) \mathrm{mmHg}$ in controls and diastolic BP was $74(67,81)$ vs 70 $(64,75) \mathrm{mmHg}$, both $P<0.001$. The prevalence of women with $\mathrm{BP} \geq 140 / 90 \mathrm{mmHg}$ was $11.1 \%(57 / 512)$ in women with PCOS vs $1.8 \%(5 / 281)$ in controls, $P<0.001$. In women $\geq 35$ years the prevalence of $B P \geq 140 / 90 \mathrm{mmHg}$ was comparable in women with PCOS and controls (12.7\% vs 9.8\%, $P=0.6)$. Using multiple regression analyses, the strongest association with BP was found for age, waist circumference, and total cholesterol in women with PCOS.

Conclusions: Normal weight women with PCOS have higher BP than controls. BP and metabolic screening are relevant also in young normal weight women with PCOS.
\end{abstract}

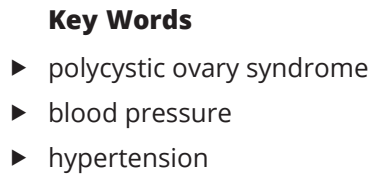

Key Words

- blood pressure

- hypertension https://ec.bioscientifica.com

https://doi.org/10.1530/EC-20-0527 (c) 2021 The authors Published by Bioscientifica Ltd

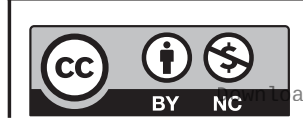

This work is licensed under a Creative Commons Attribution-NonCommercial 4.0 International License. ded from Bioscientifica.com at 04/26/2023 06:38:40AM
Endocrine Connections (2021) 10, 154-163 


\section{Introduction}

Polycystic ovary syndrome (PCOS) is the most common endocrine disorder in women of reproductive age, with a prevalence of $10-20 \%$ when the Rotterdam criteria are used (1). The PCOS diagnosis is based on at least two out of three criteria: clinical or biochemical hyperandrogenism (HA), chronic oligo-anovulation and polycystic ovaries, with exclusion of other etiologies (2).

Women with PCOS are characterized by abdominal obesity, insulin resistance, dyslipidemia, and increased risk of the metabolic syndrome, which could be associated with increased risk of cardiovascular disease (CVD) (3). The definition of the metabolic syndrome includes elevated blood pressure (BP) (3). It is estimated that more than 30\% of women with PCOS have BP > 130/85 mmHg (4) and also young women with PCOS have around three times increased risk of hypertension (HT) compared to controls $(3,5,6,7)$. In accordance, the recent international PCOS guideline recommends that $\mathrm{BP}$ should be measured by time of PCOS diagnosis, and thereafter annually in all women with PCOS (8).

The cardio-metabolic risk in PCOS could differ by PCOS phenotype, and especially the long-term cardiometabolic risk in normal weight women with PCOS is unknown. In a Danish national register-based study including 19,199 women with PCOS (9), we recently reported that the prospective risk of developing type 2 diabetes was not increased in normal weight Danish women with PCOS compared to controls (10). This has been confirmed in other studies by our group $(11,12)$. However, the risk of CVD including HT was significantly increased in women with PCOS compared to controls also after adjusting for baseline BMI (5). Furthermore, 24\% of women with PCOS in a local subset of the study cohort, who developed CVD, were lean by the time of PCOS diagnosis (5). These findings suggested that the risk of CVD including HT was attenuated but not normalized in normal weight women with PCOS. In contrast, two recent meta-analyses did not find increased risk of the metabolic syndrome including HT in normal weight women with PCOS $(7,13)$. Whether BP is higher in normal weight women with PCOS compared to controls therefore awaits clarification.

Determinants of BP in women with PCOS have not been extensively studied. Obesity is considered most important for cardio-metabolic risk in women with PCOS $(7,14)$, but the importance of BMI and/or central obesity for vascular health in normal weight women with PCOS is undetermined. Testosterone levels could be an important modifier of vascular health in PCOS, but whether testosterone has a protective or unfavorable impact on the risk of CVD in PCOS is debated $(7,15)$. We are not aware of studies investigating associations between testosterone levels and BP in normal weight study populations of women with PCOS. Furthermore, the international guidelines for PCOS recommend measurements of lipids and blood glucose in all women with PCOS (8). The importance of measuring these metabolic risk markers for vascular health in normal weight women with PCOS is debated $(10,11,16)$.

The aims of this study were (i) to investigate if normal weight women with PCOS have higher BP than controls and (ii) to investigate possible determinants for BP in normal weight women with PCOS.

\section{Materials and methods}

\section{Inclusion criteria}

Women diagnosed with PCOS from Denmark, Finland, Norway and Sweden and with available BP assessment were included in this study. All women fulfilled the Rotterdam criteria for PCOS (2) and were of Nordic origin. Data regarding lipid status, testosterone levels, and glucose tolerance in the whole study cohort have been published earlier $(11,16,17)$. Here we present data from women $\geq 20$ years of age and BMI $\leq 25 \mathrm{~kg} / \mathrm{m}^{2}$. Participants and controls were recruited from outpatient clinics, hospitals, advertisements in newspapers, hospital staff, and medical students as previously described $(11,16$, 17). The controls were recruited from outpatient clinics, hospital staff, medical students, or by advertisement.

\section{Exclusion criteria}

Women with use of hormonal contraceptives in the past 2 months prior to enrollment, ongoing pregnancy, breastfeeding, or serious endocrine disease were not included in the study. Controls had no signs or symptoms of PCOS.

The study was approved by the Ethics committee region of Southern Denmark, Ethics committee of the Northern Ostrobothnia Hospital District, Regional committee for medical and health research ethics - MidNorway, Regional committee for medical and health research ethics - South-East Norway, Ethical review committee in Uppsala, Etikprövnings-myndigheten, Stockholm and Regionala etikprövningsnämnden in 
Gothenburg (11, 16, 17). Consent has been obtained from each patient or subject after full explanation of the purpose and nature of all procedures used.

\section{Study protocol}

All women with PCOS and controls underwent clinical examination: measurement of height, weight, waist and hip circumference, Ferriman-Gallwey (FG)-score for hirsutism, and transvaginal ultrasound. Clinical hyperandrogenism (hirsutism) was diagnosed when a woman had FG-score $\geq 8$.

BP was measured while supporting the upper limb, ensuring the cuff was at heart level, using a correct size of the cuff, and not talking with the person during the process. The women avoided caffeine, smoking, and exercise for at least 30 min before the measurement.

Protocols regarding measurement of $\mathrm{BP}$ varied between the seven different sites in the following manner:

- Odense University Hospital: Patients had 10 min rest while sitting, before one measurement was recorded.

- Oulu University Hospital: Patients had 15 min rest while sitting. BP was measured twice with 1 min interval. The mean of the two measurements was recorded.

- Oslo University Hospital: Patients had 15 min rest while sitting. BP was measured twice with $2 \mathrm{~min}$ interval and the lowest BP was recorded.

- Norwegian University of Science and Technology: Patients had 10 min rest while sitting. BP was measured three times at least 2 min apart. The mean of the second and third BP measurement was used.

- Karolinska Institutet, Department of Women's and Children's Health: Patients had 5 min rest while sitting, before one measurement was recorded.

- University of Gothenburg, Sahlgrenska University Hospital: Patients had 5 min rest in a supine position. BP was measured two times with 5 min interval, and the mean was recorded.

- Uppsala University: Patients had 30 min rest while sitting. BP was measured three times with 5 min intervals and the mean was recorded.

\section{Assays}

Metabolic variables (glucose, lipid profile) were assayed by means of the routine methods used in the laboratories of the different study centers (11). Plasma total cholesterol, high-density lipoprotein (HDL), cholesterol, and triglyceride (TG) were analyzed by enzymatic colorimetric reactions (Modular P, Roche), and low-density lipoprotein (LDL) cholesterol was calculated using the Friedewald equation (18). According to the Nordic Reference Interval Project 2000, the reference ranges for the serum lipid levels were similar in all subpopulations of the study. Serum testosterone was measured by liquid chromatographymass spectrometry (LC/MS), and SHBG was measured by chemiluminometric immunoassays as reported earlier $(11,17)$. In Danish women, serum testosterone was analyzed using a specific radio-immunoassay after ether extraction (19). This method shows a close correlation with the determination of testosterone levels using mass spectrometry (19).

Free androgen index (FAI) was calculated by dividing total testosterone with SHBG and multiplying by 100.

\section{Statistics}

The primary study outcome was BP. We aimed to compare differences in BP between normal weight women with PCOS vs controls and determinants of BP in women with PCOS. Given the inconsistency of previous study findings in lean women with PCOS, we did not perform a power calculation. We wanted to study two comparable groups with respect to age and BMI distribution in the patient and control groups. Hence, 512 women with PCOS were matched individually with one woman in the control group ( $n=281$ ) according to age (age range $20-57$ years), and BMI (range 18.8-24.8 kg/m² in the PCOS group and $18.7-24.7 \mathrm{~kg} / \mathrm{m}^{2}$ in the control group, 2.5-97.5 percentile interval). Matching was performed according to the nearest year of birth and BMI unit.

Epidemiological studies have evaluated the association of SBP, DBP, pulse pressure, mean BP, and mid/BP with CVD outcomes. Among these, SBP and DBP are consistently best associated with CVD risk and are prioritized in this study $(20,21)$. BP 140/90 was used as threshold BP according to the European guidelines (22). Data are presented as median (quartiles) and $n(\%)$. Differences between women with PCOS and controls were evaluated by Mann-Whitney test (continuous variables) and Chi-square test. Country of inclusion was taken into account by entering country code as an independent variable (1: Denmark, 2: Finland, 3: Norway, 4: Sweden). In these analyses, we entered clinical relevant study outcome (BP, age, etc.) as the dependent variable and country code and patient/controls as independent variables.

Several of the biochemical markers exhibited some deviation from a Gaussian distribution and we examined

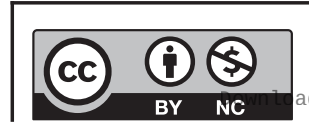

This work is licensed under a Creative Commons Attribution-NonCommercial 4.0 International License. ded from Bioscientifica.com at 04/26/2023 06:38:40AM via free access 
bivariate association between DBP, SBP, clinical, and biochemical characteristics in women with PCOS and in controls separately by non-parametric Spearman correlation (r-values and $P$-levels).

Multiple linear regression analysis was used to examine the effect of lipid status, glucose status, and testosterone on SBP and DBP, respectively, in women with PCOS. Variables included in the regression analyses were selected based on closest association with SBP and DBP, respectively, based on results from bivariate correlation analyzes. The clinical setting differed at the study centers, and country code was entered as an independent variable in regression analyses. All models were corrected for age, waist circumference, and country of study inclusion (1: Denmark, 2: Finland, 3: Norway, 4: Sweden). Data were presented as $\beta$-coefficients (95\% CI) and adjusted $\mathrm{R}^{2}$ values. In all regression models, model assumptions were validated through comprehensive residual analyses, as well as inspection of linearity and homogeneity of variance, and multicollinearity was assessed through variance inflation factors.

IBM SPSS statistics 25 statistical package was used. A $P$-value $<0.05$ was considered significant.

\section{Results}

Clinical and biochemical characteristics of women with PCOS and age- and weight-matched controls are presented in Table 1 . The number of patients included from Denmark was $n=175$ (one study center), Sweden $n=102$ (three study centers), Norway $n=85$ (two study centers), and Finland $n=149$ (one study center).

SBP and DBP were significantly higher in women with PCOS compared to controls.

Total testosterone, FAI, and HbA1c were higher, and SHBG levels were lower in women with PCOS vs controls, whereas waist circumference, WHR, lipid status, and fasting BG were comparable in the two study cohorts. All results, except $\mathrm{HbA1c}$, remained significant after adjusting for country of study inclusion (Table 1 ).

The prevalence of $\mathrm{BP} \geq 140 / 90 \mathrm{mmHg}$ in different age groups in women with PCOS and controls is shown in Table 2 . BP $\geq 140 / 90 \mathrm{mmHg}$ was observed in $11.1 \%$ (57/512) women with PCOS compared to $1.8 \%(5 / 281)$ controls. Furthermore, both SBP $\geq 140 \mathrm{mmHg}$ (8.2\% PCOS vs $1.7 \%$ controls) and DBP $\geq 90 \mathrm{mmHg}(7.4 \%$ PCOS vs $0.3 \%$ controls) were higher than in controls. In women $<35$ years, the prevalence of $\mathrm{BP} \geq 140 / 90 \mathrm{mmHg}$ was $10.9 \%$ (47/433) in women with PCOS compared to 0\% $(0 / 230)$ in controls, $P<0.001$. In women $\geq 35$ years the prevalence of $\mathrm{BP} \geq 140 / 90 \mathrm{mmHg}$ was $12.7 \%(10 / 79)$ in women with PCOS compared to $9.8 \%(5 / 51)$ in controls, $P=0.62$.

Characteristics in women with PCOS according to $\mathrm{BP}<$ or $\geq 140 / 90 \mathrm{mmHg}$ are shown in Table 3. Women with $\mathrm{BP} \geq 140 / 90 \mathrm{mmHg}$ had higher waist circumference,

Table 1 Characteristics of normal-weight women with PCOS and age and BMI matched controls.

\begin{tabular}{|c|c|c|c|c|}
\hline & \multicolumn{2}{|r|}{ Pcos } & \multicolumn{2}{|l|}{ Controls } \\
\hline & $n$ & & & $n$ \\
\hline SBP (mmHg) & 512 & $118(109,128)$ & $110(105,120)$ & 281 \\
\hline DBP (mmHg) & 512 & $74(67,81)$ & $70(64,75)$ & 281 \\
\hline Age (years) & 512 & $28(25,32)$ & $27(24,31)$ & 281 \\
\hline $\mathrm{BMI}\left(\mathrm{kg} / \mathrm{m}^{2}\right)$ & 512 & $22.2(20.7,23.4)$ & $22.0(20.5,23.3)$ & 281 \\
\hline Waist & 472 & $77(72,81)$ & $76(73,81)$ & 123 \\
\hline WHR & 466 & $0.77(0.74,0.83)$ & $0.77(0.75,0.82)$ & 123 \\
\hline FG score & 293 & $4(2,8)$ & 0 & 118 \\
\hline T-testosterone (nmol/L) & 360 & $1.5(1.1,2.0)$ & $0.8(0.6,1.0)$ & 248 \\
\hline SHBG (nmol/L) & 484 & $54(41,71)$ & $71(56,93)$ & 246 \\
\hline Androgen index & 339 & $0.26(0.17,0.43)$ & $0.11(0.08,0.15)$ & 246 \\
\hline Cholesterol (mmol/L) & 326 & $4.4(3.9,5.0)$ & $4.5(3.9,5.0)$ & 111 \\
\hline TG (mmol/L) & 323 & $0.8(0.6,1.0)$ & $0.8(0.6,0.9)$ & 111 \\
\hline LDL (mmol/L) & 298 & $2.4(2.0,2.9)$ & $2.4(1.9,2.9)$ & 111 \\
\hline HDL (mmol/L) & 306 & $1.6(1.4,1.8)$ & $1.6(1.4,1.9)$ & 111 \\
\hline BG fasting (mmol/L) & 395 & $4.8(4.6,5.1)$ & $4.9(4.5,5.2)$ & 93 \\
\hline HbA1c (\%) & 205 & $5.2(4.9,5.3)$ & $4.8(4.7,5.0)$ & 43 \\
\hline Smoking (yes), $n(\%)$ & 447 & $64(14.3 \%)$ & $10(9.4 \%)$ & 106 \\
\hline Anovulation (yes), $n(\%)$ & 506 & $430(84.9 \%)$ & & \\
\hline PCOS (yes), $n(\%)$ & 477 & $406(85.1 \%)$ & & \\
\hline HA (yes), $n(\%)$ & 475 & $269(56.6 \%)$ & & \\
\hline PCOS + anov (yes), $n(\%)$ & 426 & $219(51.4 \%)$ & & \\
\hline
\end{tabular}

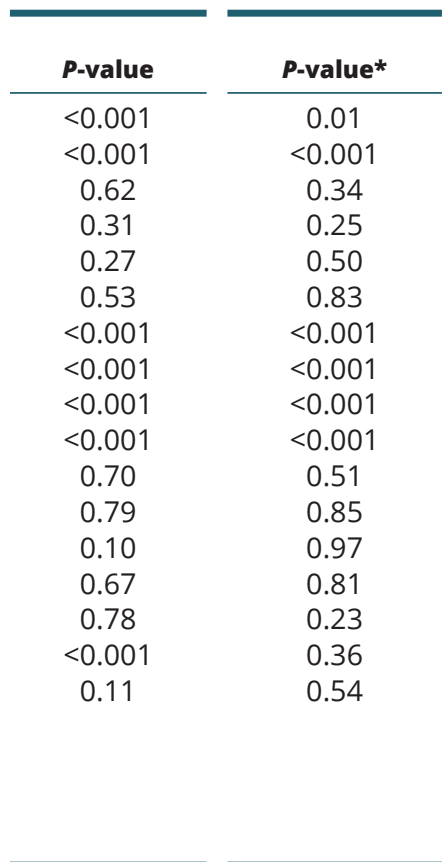

Data presented as median (interquartile range) or $n(\%) . P$-values between women with PCOS and controls.

${ }^{\star} P$-value adjusted for country of study-inclusion (1: Denmark, 2: Finland, 3: Norway, 4: Sweden).

https://ec.bioscientifica.com

https://doi.org/10.1530/EC-20-0527 (c) 2021 The authors Published by Bioscientifica Ltd

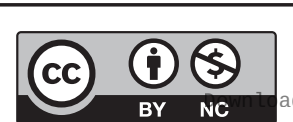

This work is licensed under a Creative Commons Attribution-NonCommercial 4.0 International License. ded from Bioscientifica,com at 04/26/2023 06:38:40AM via free access 
Table 2 Number and percentage of women with PCOS and controls with blood pressure $\geq 140 / 90$ according to age $(n=512$ PCOS, 281 controls).

\begin{tabular}{|c|c|c|}
\hline \multirow[b]{2}{*}{ Age (years) } & \multicolumn{2}{|c|}{$S B P \geq 140 \mathrm{mmHg}$} \\
\hline & PCOS & Control \\
\hline$<25$ & $8 / 110$ & 0/81 \\
\hline $25-29$ & $14 / 199$ & 0/109 \\
\hline $30-34$ & $12 / 124$ & $0 / 40$ \\
\hline $35-39$ & 5/59 & $2 / 29$ \\
\hline$\geq 40$ & $3 / 20$ & $3 / 22$ \\
\hline Total & $42 / 512(8.2 \%)$ & $5 / 281(1.7 \%)$ \\
\hline Chi test & $<0.003$ & \\
\hline
\end{tabular}

\begin{tabular}{cc}
\hline \multicolumn{2}{c}{ DBP $\geq \mathbf{9 0} \mathbf{~ m m H g}$} \\
\hline PCOS & Control \\
\cline { 1 - 1 } $7 / 110$ & $0 / 81$ \\
$11 / 199$ & $0 / 109$ \\
$13 / 124$ & $0 / 40$ \\
$5 / 59$ & $0 / 29$ \\
$2 / 20$ & $1 / 22$ \\
$38 / 512(7.4 \%)$ & $1 / 281(0.3 \%)$ \\
$<0.01$ & \\
\hline
\end{tabular}

\begin{tabular}{ccc}
\hline \multicolumn{2}{c}{$\mathbf{B P} \geq \mathbf{1 4 0 / 9 0} \mathbf{~ m m H g}$} \\
\hline PCOS & & Control \\
\cline { 1 - 1 } $12 / 110$ & $0 / 81$ \\
$18 / 199$ & $0 / 109$ \\
$17 / 124$ & $0 / 40$ \\
$7 / 59$ & $2 / 29$ \\
$3 / 20$ & $3 / 22$ \\
$57 / 512(11.1 \%)$ & $5 / 281(1.8 \%)$ \\
$<0.001$ & \\
\hline
\end{tabular}

Chi test performed within each BP group (SBP, DBP, and BP) PCOS vs controls.

WHR, FAI, total cholesterol, fasting BG, and lower rate of anovulation and polycystic ovaries compared to women with $\mathrm{BP}<140 / 90 \mathrm{mmHg}$.

Bivariate associations with BP are shown in Table 4. In women with PCOS, SBP, and DBP were positively correlated with BMI, waist circumference, WHR, total testosterone, lipid status (total cholesterol, TG, LDL), and fasting BG. The highest R-values were found for WHR, lipid status, and fasting BG. In controls, the highest R-values were found in associations between BP and age, BMI, waist circumference, and WHR.

Multiple regression analyses in women with PCOS are shown in Tables 5 and 6.
SBP

Age and waist were significant predictors of SBP in the crude model. In adjusted analyses, the best individual marker of SBP was age and cholesterol. The $\mathrm{R}^{2}$ value of the fully adjusted model was 0.39 .

\section{DBP}

Waist circumference and age was significantly associated with DBP in the crude model. In adjusted analyses, the best individual marker of DBP was cholesterol. The $\mathrm{R}^{2}$ value of the fully adjusted model was 0.39 .

Table 3 Characteristics in women with PCOS divided according to BP ( $n=512)$.

\begin{tabular}{l} 
\\
\hline SBP (mmHg) \\
DBP (mmHg) \\
Age (years) \\
BMI (kg/m²) \\
Waist (cm) \\
WHR \\
FG score \\
T-testosterone (nmol/L) \\
SHBG (nmol/L) \\
FAl \\
Cholesterol (mmol/L) \\
TG (mmol/L) \\
LDL (mmol/L) \\
HDL (mmol/L) \\
Fasting BG (mmol/L) \\
HbA1c (\%) \\
Smoking (yes) \\
Anovulation (yes) \\
PCO (yes) \\
HA (yes) \\
HA + anovulation (yes) \\
Ho
\end{tabular}

\begin{tabular}{|c|c|}
\hline & $B P \geq 140 / 90$ \\
\hline \multicolumn{2}{|c|}{$n$} \\
\hline 57 & $142(138,150)$ \\
\hline 67 & $92(86,96)$ \\
\hline 57 & $29(26,34)$ \\
\hline 57 & $22.5(20.9,24.0)$ \\
\hline 53 & $80(73,85)$ \\
\hline 52 & $0.80(0.76,0.85)$ \\
\hline 21 & $3(1,7)$ \\
\hline 46 & $1.60(1.25,2.27)$ \\
\hline 62 & $54(41,77)$ \\
\hline 32 & $0.36(0.19,0.47)$ \\
\hline 40 & $4.8(4.1,5.4)$ \\
\hline 39 & $0.8(0.6,0.9)$ \\
\hline 39 & $2.6(2.1,3.3)$ \\
\hline 39 & $1.7(1.4,1.9)$ \\
\hline 40 & $5.2(4.8,5.3)$ \\
\hline 32 & $5.2(5.0,5.4)$ \\
\hline 48 & $8(16.7 \%)$ \\
\hline 56 & 42 (75.0\%) \\
\hline 51 & 36 (70.5\%) \\
\hline 47 & 30 (63.8\%) \\
\hline 40 & 21 (52.5\%) \\
\hline
\end{tabular}

\begin{tabular}{c} 
BP < 140/90 \\
\hline $116(108,124)$ \\
$72(67,80)$ \\
$28(25,32)$ \\
$22.1(20.7,23.3)$ \\
$76(71,81)$ \\
$0.77(0.73,0.83)$ \\
$4(2,8)$ \\
$1.50(1.10,2.00)$ \\
$53(39,70)$ \\
$0.26(0.17,0.42)$ \\
$4.4(3.9,4.9)$ \\
$0.7(0.6,1.0)$ \\
$2.4(1.9,2.9)$ \\
$1.6(1.4,1.8)$ \\
$4.8(4.5,5.1)$ \\
$5.2(4.9,5.3)$ \\
$56(14.0 \%)$ \\
$388(86.2 \%)$ \\
$370(86.9 \%)$ \\
$239(55.8 \%)$ \\
$198(51.3 \%)$
\end{tabular}

$\begin{array}{r} \\ \hline n \\ \hline 455 \\ 455 \\ 455 \\ 455 \\ 419 \\ 414 \\ 272 \\ 359 \\ 485 \\ 307 \\ 286 \\ 259 \\ 267 \\ 314 \\ 173 \\ 205 \\ 399 \\ 450 \\ 426 \\ 428 \\ 386 \\ \hline\end{array}$

\begin{tabular}{c}
\hline P-value \\
\hline$<0.001$ \\
$<0.001$ \\
0.16 \\
0.14 \\
0.02 \\
0.02 \\
0.40 \\
0.14 \\
0.63 \\
0.04 \\
0.01 \\
0.54 \\
0.06 \\
0.25 \\
$<0.001$ \\
0.90 \\
0.84 \\
0.04 \\
0.005 \\
0.29 \\
0.89 \\
\hline
\end{tabular}

Data presented as median (interquartile range) or $n(\%)$. P-values between women with elevated BP and normal BP.

https://ec.bioscientifica.com
https://doi.org/10.1530/EC-20-0527 2021 The authors
Published by Bioscientifica Ltd

This work is licensed under a Creative Commons Attribution-NonCommercial 4.0 International License. 
Table 4 Bivariate associations with BP in women with PCOS and controls.

\begin{tabular}{|c|c|c|c|c|c|c|}
\hline & \multirow[b]{2}{*}{$n$} & \multicolumn{2}{|c|}{ Pcos } & \multicolumn{2}{|c|}{ Control } & \multirow[b]{2}{*}{$n$} \\
\hline & & SBP & DBP & SBP & DBP & \\
\hline Age (years) & 512 & $0.07(0.13)$ & $0.10(0.02)$ & $0.19(0.001)$ & $0.28(<0.001)$ & 281 \\
\hline $\mathrm{BMI}\left(\mathrm{kg} / \mathrm{m}^{2}\right)$ & 512 & $0.15(0.001)$ & $0.13(0.003)$ & $0.19(0.002)$ & $0.11(0.06)$ & 281 \\
\hline Waist (cm) & 472 & $0.15(0.001)$ & $0.15(0.001)$ & $0.36(<0.001)$ & $0.27(<0.007)$ & 123 \\
\hline WHR & 466 & $0.19(<0.001)$ & $0.20(<0.001)$ & $0.39(<0.001)$ & $0.31(<0.001)$ & 123 \\
\hline T-testosterone (nmol/L) & 360 & $0.14(0.009)$ & $0.11(0.03)$ & $-0.03(0.67)$ & $-0.02(0.75)$ & 248 \\
\hline Androgen Index & 339 & $0.10(0.07)$ & $0.13(0.02)$ & $0.04(0.58)$ & $0.07(0.28)$ & 246 \\
\hline Cholesterol (mmol/L) & 326 & $0.23(<0.001)$ & $0.20(<0.001)$ & $0.06(0.52)$ & $0.17(0.08)$ & 111 \\
\hline $\mathrm{TG}(\mathrm{mmol} / \mathrm{L})$ & 323 & $0.10(0.06)$ & $0.07(0.19)$ & $0.21(0.03)$ & $0.08(0.39)$ & 111 \\
\hline LDL (mmol/L) & 298 & $0.22(<0.001)$ & $0.19(<0.001)$ & $0.11(0.24)$ & $0.06(0.51)$ & 111 \\
\hline $\mathrm{HDL}(\mathrm{mmol} / \mathrm{L})$ & 306 & $0.04(0.49)$ & $0.05(0.40)$ & $0.09(0.32)$ & $0.22(0.02)$ & 111 \\
\hline Fasting BG (mmol/L) & 395 & $0.28(<0.001)$ & $0.19(<0.001)$ & $0.05(0.65)$ & $-0.08(0.43)$ & 93 \\
\hline $\mathrm{HbA} 1 \mathrm{c}(\%)$ & 205 & $0.03(0.69)$ & $0.06(0.44)$ & $0.31(0.15)$ & $0.21(0.33)$ & 43 \\
\hline
\end{tabular}

Non-parametric associations between DBP, SBP, clinical, and biochemical characteristics in women with PCOS. Data presented as R-value (P).

\section{Discussion}

In the present study, BP was significantly higher in young, normal weight women with PCOS compared to controls. In women with PCOS, higher BP was associated with greater waist circumference and unfavorable cholesterol, which supported the importance of metabolic screening. Testosterone levels were not associated with BP in women with PCOS.

Our finding of higher BP in normal weight Scandinavian women with PCOS is supported by recent studies. Ollila et al. (6) studied PCOS as an independent risk factor for HT in normal weight women with self-reported PCOS $(n=100)$ in a population based cross-sectional study from the Northern Finland Birth Cohort. Ollila found that women with self-reported PCOS displayed higher BP by the age of 31 compared to controls (mean (s.D.) SBP 120 (13) vs 117 (11) $\mathrm{mmHg}, P=0.017$ and DBP 76 (10) vs 72 (10) $\mathrm{mmHg}, P=0.003$ ) (6). Moreover, PCOS was associated with HT and increased cardiovascular morbidity independent of BMI (6). Pinola et al. found that overweight and obese Scandinavian women with PCOS (mean BMI $29 \mathrm{~kg} / \mathrm{m}^{2}$ ) had $5 \mathrm{mmHg}$ higher SBP and $4 \mathrm{mmHg}$ higher DBP compared to controls, which was present already from $<30$ years of age (17). Higher BP in women with PCOS remained significant after adjustment for BMI and age (17). Recently, we performed a national register based study in a Danish cohort of 18,112 women with PCOS and 52,769 controls where the main study outcome was CVD events including HT and dyslipidemia (5). Included women had average age of 29 years and median follow up of 11.1 years (5). The odds ratio for development of CVD including HT and dyslipidemia was 1.7 in PCOS and the risk of HT was dependent on baseline metabolic risk profile (SBP and DBP, BMI, waist, and triglycerides) (5). A total of $24 \%$ of women with PCOS and CVD were normal weight at the time of PCOS diagnosis (5). Holte et al. applied $24 \mathrm{~h} \mathrm{BP}$ measurements and found significantly

Table 5 Predictors of SBP, multiple regression analyses in women with PCOS $(n=512)$.

\begin{tabular}{|c|c|c|c|c|c|}
\hline & Model $1(n=472)$ & Model $2(n=374)$ & Model $3(n=299)$ & Model $4(n=343)$ & Model $5(n=130)$ \\
\hline Age & $\begin{array}{l}0.31(0.07 ; 0.56) \\
P=0.01\end{array}$ & $\begin{array}{l}0.40(0.12 ; 0.67) \\
P=0.007\end{array}$ & $\begin{array}{l}0.27(-0.02 ; 0.57) \\
P=0.07\end{array}$ & $\begin{array}{l}0.42(0.14 ; 0.69) \\
P=0.04\end{array}$ & $\begin{array}{l}0.43(0.008 ; 0.86) \\
P=0.04\end{array}$ \\
\hline Waist & $\begin{array}{l}0.36(0.21 ; 0.52) \\
P<0.001\end{array}$ & $\begin{array}{l}0.34(0.18 ; 0.50) \\
P<0.001\end{array}$ & $\begin{array}{l}0.31(0.13 ; 0.50) \\
P=0.0 .1\end{array}$ & $\begin{array}{l}0.31(0.10 ; 0.51) \\
P=0.004\end{array}$ & $\begin{array}{l}0.12(-0.22 ; 0.47) \\
P=0.47\end{array}$ \\
\hline Fasting BG & $X$ & $\begin{array}{l}2.1(-0.7 ; 4.9) \\
P=0.14\end{array}$ & $X$ & $X$ & $\begin{array}{l}-0.89(-5.3 ; 3.5) \\
P=0.69\end{array}$ \\
\hline Cholesterol & $x$ & $X$ & $\begin{array}{l}3.9(1.9 ; 6.0) \\
(P<0.001)\end{array}$ & $X$ & $\begin{array}{l}4.2(0.2 ; 8.1) \\
P=0.04\end{array}$ \\
\hline T-Testosterone & $X$ & $X$ & $X$ & $\begin{array}{l}1.4(-0.3 ; 3.1) \\
P=0.11\end{array}$ & $\begin{array}{l}1.2(-1.4 ; 3.8) \\
P=0.40\end{array}$ \\
\hline $\mathbf{R}^{2}$ & $0.15(P<0.001)$ & $0.16(P<0.001)$ & $0.23(P<0.001)$ & $0.24(P<0.001)$ & $0.39(P<0.001)$ \\
\hline
\end{tabular}

Data represent $\beta$-coefficients $(95 \% \mathrm{Cl})$ and adjusted $\mathrm{R}^{2}$ values. All models were adjusted for country of origin (1: Denmark, 2: Finland, 3: Norway, 4: Sweden), age, and waist circumference. In model 3, 4, 5, additional independent variables included fasting blood glucose (BG), cholesterol, and total testosterone (T-testosterone), as shown in the respective models above. Bold indicates statistical significance.

https://ec.bioscientifica.com https://doi.org/10.1530/EC-20-0527 (c) 2021 The authors Published by Bioscientifica Ltd

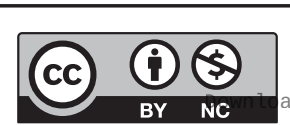

This work is licensed under a Creative Commons Attribution-NonCommercial 4.0 International License. ed from Bioscientifica.com at 04/26/2023 06:38:40AM via free access 
Table 6 Predictors of DBP, multiple regression analyses in women with PCOS $(n=512)$

\begin{tabular}{|c|c|c|c|c|c|}
\hline & Model $1(n=472)$ & Model $2(n=374)$ & Model $3(n=299)$ & Model $4(n=343)$ & Model $5(n=130)$ \\
\hline Age & $\begin{array}{l}0.32(0.14 ; 0.50) \\
P<0.001\end{array}$ & $\begin{array}{l}0.37(0.17 ; 0.57) \\
P=0.004\end{array}$ & $\begin{array}{l}0.26(0.05 ; 0.46) \\
P=0.01\end{array}$ & $\begin{array}{l}0.46(0.25 ; 0.67) \\
P<0.001\end{array}$ & $\begin{array}{l}0.46(0.16 ; 0.77) \\
P=0.003\end{array}$ \\
\hline Waist & $\begin{array}{l}0.23(0.12 ; 0.34) \\
P<0.001\end{array}$ & $\begin{array}{l}0.25(0.14 ; 0.38) \\
P=0.001\end{array}$ & $\begin{array}{l}0.15(0.03 ; 0.29) \\
P=0.01\end{array}$ & $\begin{array}{l}0.23(0.07 ; 0.38) \\
P=0.07\end{array}$ & $\begin{array}{l}0.01(-0.23 ; 0.26) \\
P=0.91\end{array}$ \\
\hline F-Glucose & $X$ & $\begin{array}{l}-0.23(-2.2 ; 1.8) \\
P=0.82\end{array}$ & X & X & $\begin{array}{l}0.11(-3.0 ; 3.3) \\
P=0.94\end{array}$ \\
\hline Cholesterol & $X$ & $X$ & $\begin{array}{l}1.9(0.47 ; 3.3) \\
(P<0.001)\end{array}$ & $X$ & $\begin{array}{l}2.4(-0.40 ; 5.2) \\
P=0.09\end{array}$ \\
\hline T-Testosterone & $x$ & $x$ & $x$ & $\begin{array}{l}0.75(-0.55 ; 2.0) \\
P=0.56\end{array}$ & $\begin{array}{l}0.15(-0.17 ; 2.0) \\
P=0.87\end{array}$ \\
\hline $\mathbf{R}^{2}$ & $0.15(P<0.001)$ & $0.16(P<0.001)$ & $0.21(P<0.001)$ & $0.23(P<0.001)$ & $0.39(P<0.001)$ \\
\hline
\end{tabular}

Data represent $\beta$-coefficients $(95 \% \mathrm{Cl})$ and adjusted $\mathrm{R}^{2}$ values. All models were adjusted for country of origin (1: Denmark, 2: Finland, 3: Norway, 4: Sweden), age and, waist circumference. In model 3, 4, 5, additional independent variables included fasting blood glucose (BG), cholesterol, and total testosterone (T-testosterone), as shown in the respective models above. Bold indicates statistical significance.

higher day-time systolic BP in Swedish women with PCOS (mean BMI $26 \mathrm{~kg} / \mathrm{m}^{2}$ ), which persisted after adjusting for BMI, body fat distribution, and insulin resistance (23). In populations of other ethnic background than Nordic, Zachurzok-Buczynska et al. reported higher 24-h BP and higher day and night mean arterial BP in normal weight Polish women with PCOS compared to controls (24) and Bahri Khomami et al. found higher SBP in Iranian women with PCOS (mean BMI $26 \mathrm{~kg} / \mathrm{m}^{2}$ ) compared to controls (25). Joham et al. conducted a cross sectional study in 8612 Australian women (500 women with PCOS, average BMI $28 \mathrm{~kg} / \mathrm{m}^{2}$ ) and found higher risk of HT in normal weight women with PCOS vs controls (26). In regression analyses, there was a trend toward an association between PCOS and HT (odds ratio: 1.6, 95\% CI: 0.9-2.6, $P=0.09$ ), yet this did not reach significance (26). In contrast, other studies reported comparable BP in normal weight women with PCOS (originating from China (27) and Spain (28)) compared to controls. A recent meta-analysis found no difference in HT in non-obese women with and without PCOS (13). The number of participants included in the meta-analysis was limited, which resulted in a very wide CI for the odds ratio of HT in normal weight women with PCOS compared to controls $2.44(0.80,7.43), P=0.11$ (13). Among BMI-matched studies, Lim et al. performed subgroup analyses according to geographic region and found a significantly increased risk of metabolic syndrome in normal weight women with PCOS from Europe, but not from other regions (7). Furthermore, the greatest increase in prevalence of metabolic syndrome in women with PCOS compared to controls was in American study populations, which the authors suggested was likely to be related to obesity (7). Whether the metabolic risk profile in European women with PCOS differs from women with
PCOS originating from other continents remains to be determined.

BP increased with age in the present study. Interestingly, the prevalence of $\mathrm{BP}>140 / 90 \mathrm{mmHg}$ was different between women with PCOS and controls. No control women with BMI $<25 \mathrm{~kg} / \mathrm{m}^{2}$ and age $<35$ years had $\mathrm{BP} \geq 140 / 90 \mathrm{mmHg}$, while the corresponding prevalence in women with PCOS was $10.9 \%$. This finding supported that young normal-weight women with PCOS need attention regarding BP measurement. The absolute level of SBP and DBP was not remarkably high. In European guidelines, BP lowering drug treatment is recommended with office $\mathrm{BP} \geq 140 / 90 \mathrm{mmHg}$ and $>5 \%$ fatal CVD risk (22). However, previous studies reported that the risk for CVD increases in a log-linear fashion already from SBP levels $<115 \mathrm{mmHg}$ to $>180 \mathrm{mmHg}$, and from DBP levels $<75 \mathrm{mmHg}$ to $>105 \mathrm{mmHg}(29,30)$. These risk gradients were homogenous across subgroups of sex and ethnicity (29).

Waist circumference and lipid status were the most important determinants of BP in our normal weight study cohort of women with PCOS. These findings were in accordance with studies in populations without PCOS that showed a close relation between BMI and BP with no evidence of a threshold for BMI (31). Furthermore, for cholesterol levels in the range 5.2-11.6 $\mathrm{mmol} / \mathrm{L}$, each $1 \mathrm{mmol} / \mathrm{L}$ increase was associated with 7\% higher mortality (32). Recent findings suggested that young individuals are more affected by higher lipid levels than older individuals. In the age groups of 18-34, 35-44, 45-54, 55-64, 65-74, and 75-99 years, each $1 \mathrm{mmol} / \mathrm{L}$ higher level for total cholesterol $\geq 5.2 \mathrm{mmol} / \mathrm{L}$, increased mortality by $14,13,8,7,6$, and $3 \%$, respectively (32). HbA1c and blood glucose is associated with all-cause https://ec.bioscientifica.com

https://doi.org/10.1530/EC-20-0527 (c) 2021 The authors Published by Bioscientifica Ltd
This work is licensed under a Creative Commons Attribution-NonCommercial 4.0 International License. ed from Bioscientifica.com at 04/26/2023 06:38:40AM via free access 
mortality also in individuals without T2D $(33,34)$, and the association between glucose and mortality is closer at younger ages (35). Our findings suggest that the same metabolic risk markers are relevant in women with PCOS as in other study populations. Our results demonstrate that waist circumference and lipid status have the highest impact on SBP, supporting the hypothesis that lifestyle intervention is important also in young and normal weight women with PCOS. Furthermore, intervention against metabolic risk could be of special relevance in young study cohorts, especially if BP is increased (16). We did not standardize insulin measurement across counties, and therefore, these data were not included in the present manuscript. Insulin resistance could be a mediator of metabolic risk in women with PCOS (36) and this hypothesis should be further evaluated in future studies. Obstructive sleep apnea is associated with higher risk of metabolic disease including HT (37). The risk of obstructive sleep apnea in normal weight women with PCOS and HT should be further investigated in future studies.

Testosterone showed a positive association with BP in bivariate analyses. In regression analyses, however, the impact of testosterone on BP was not significant. These results could be explained by an interaction between higher testosterone, central obesity, and metabolic risk, which is also observed in obese women with PCOS (4). In accordance, Pinola et al. (17) found that higher BP in women with PCOS was not related to whether the women were normo- or hyperandrogenic. Androgen levels decline in ageing women with PCOS $(38,39)$ and the impact of testosterone on BP in ageing women with PCOS could decline compared to metabolic risk factors such as central obesity, lipid status, and blood glucose levels.

Strengths and limitations apply to the present study. We included a large and well-characterized study population of homogenous ethnicity, which was a major strength of the study. However, the study cohort included women referred to outpatient clinics, which could imply a more severe PCOS phenotype. The women participating in the present study were included in other publications from the author group $(11,16,17)$, which could infer study bias. We only allowed gold standard steroid measurements in the present study (mass spectrometry or ether extraction followed by RIA), but differences in applied steroid analyses between study centers could have affected study results. In regression analyses, we corrected for country of diagnosis, but we have been cautious regarding conclusions including results from these measurements.
A major limitation of this study was that seven different study centers were involved, which implied different methods of BP measurement and in most cases only one office BP measurement was performed. The applied methods in all centers resembled methods for measuring BP in a daily clinic, which may represent a study strength. However, it is important to recognize that diagnosis and classification of elevated BP should be based on $\geq 2$ readings obtained on $\geq 2$ occasions in order not to overestimate the prevalence of HT (20). BP measurements were obtained in a similar way in women with PCOS and controls and the limitation of only one BP measurement did not affect the observed differences between the study cohorts. However, the current study design does not allow us to draw conclusions on the prevalence of diagnosis of HT and indication for medical treatment for HT in the study cohort. Furthermore, the study should be repeated in populations of other ethnic background.

Taken together, we found that young and normal weight women with PCOS had higher BP compared to age and BMI matched controls. In women with PCOS, BP was positively associated with waist and lipid status, which underlined the importance of metabolic screening also in young and normal weight women with PCOS.

\section{Declaration of interest}

The authors declare that there is no conflict of interest that could be perceived as prejudicing the impartiality of the research reported.

\section{Funding}

This research did not receive any specific grant from any funding agency in the public, commercial or not-for-profit sector.

\section{Author contribution statement}

All authors contributed to the conception and design of the study, acquisition of data, analysis of data, drafting the article and final approval of the version to be published.

\section{References}

1 Conway G, Dewailly D, Diamanti-Kandarakis E, Escobar-Morreale HF Franks S, Gambineri A, Kelestimur F, Macut D, Micic D, Pasquali R, et al. The polycystic ovary syndrome: a position statement from the European Society of Endocrinology. European Journal of Endocrinology 2014171 P1-29. (https://doi.org/10.1530/EJE-14-0253)

2 Rotterdam ESHRE/ASRM-Sponsored PCOS Consensus Workshop Group. Revised 2003 consensus on diagnostic criteria and long-term health risks related to polycystic ovary syndrome. Fertility and Sterility 200481 19-25. (https://doi.org/10.1016/j.fertnstert.2003.10.004)

3 Glintborg D. Endocrine and metabolic characteristics in polycystic ovary syndrome. Danish Medical Journal 201663 B5232.

4 Glintborg D \& Andersen M. MANAGEMENT OF ENDOCRINE DISEASE: Morbidity in polycystic ovary syndrome. European Journal

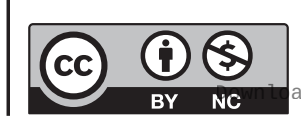

This work is licensed under a Creative Commons Attribution-NonCommercial 4.0 International License. Atribution- Bioscientifica com at 04/26/2023 06:38:40AM via free access 
of Endocrinology 2017176 R53-R65. (https://doi.org/10.1530/ EJE-16-0373)

5 Glintborg D, Rubin KH, Nybo M, Abrahamsen B \& Andersen M. Cardiovascular disease in a nationwide population of Danish women with polycystic ovary syndrome. Cardiovascular Diabetology 201817 37. (https://doi.org/10.1186/s12933-018-0680-5)

6 Ollila ME, Kaikkonen K, Jarvelin MR, Huikuri HV, Tapanainen JS, Franks S, Piltonen TT \& Morin-Papunen L. Self-reported polycystic ovary syndrome is associated with hypertension: a Northern Finland Birth Cohort 1966 study. Journal of Clinical Endocrinology and Metabolism 2019104 1221-1231. (https://doi.org/10.1210/jc.201800570)

7 Lim SS, Kakoly NS, Tan JWJ, Fitzgerald G, Bahri Khomami M, Joham AE, Cooray SD, Misso ML, Norman RJ, Harrison CL, et al. Metabolic syndrome in polycystic ovary syndrome: a systematic review, meta-analysis and meta-regression. Obesity Reviews 201920 339-352. (https://doi.org/10.1111/obr.12762)

8 Teede HJ, Misso ML, Costello MF, Dokras A, Laven J, Moran L, Piltonen T, Norman RJ \& International PCOS Network. Recommendations from the international evidence-based guideline for the assessment and management of polycystic ovary syndrome. Human Reproduction 201833 1602-1618. (https:/doi.org/10.1093/ humrep/dey256)

9 Glintborg D, Hass Rubin K, Nybo M, Abrahamsen B \& Andersen M. Morbidity and medicine prescriptions in a nationwide Danish population of patients diagnosed with polycystic ovary syndrome. European Journal of Endocrinology 2015172 627-638. (https://doi. org/10.1530/EJE-14-1108)

10 Glintborg D, Rubin KH, Abrahamsen B \& Andersen M. Response to letter to the editor: 'development and risk factors of Type 2 diabetes in a nationwide population of women with polycystic ovary syndrome'. Journal of Clinical Endocrinology and Metabolism 2018103 362-363. (https://doi.org/10.1210/jc.2017-02123)

11 Pelanis R, Mellembakken JR, Sundstrom-Poromaa I, Ravn P, MorinPapunen L, Tapanainen JS, Piltonen T, Puurunen J, Hirschberg AL, Fedorcsak $\mathrm{P}$, et al. The prevalence of Type 2 diabetes is not increased in normal-weight women with PCOS. Human Reproduction 201732 2279-2286. (https://doi.org/10.1093/humrep/dex294)

12 Ollila MM, West S, Keinanen-Kiukaanniemi S, Jokelainen J, Auvinen J, Puukka K, Ruokonen A, Jarvelin MR, Tapanainen JS, Franks S, et al. Overweight and obese but not normal weight women with PCOS are at increased risk of type 2 diabetes mellitus-a prospective, population-based cohort study. Human Reproduction 201732 423-431. (https://doi.org/10.1093/humrep/dew329)

13 Zhu S, Zhang B, Jiang X, Li Z, Zhao S, Cui L \& Chen ZJ. Metabolic disturbances in non-obese women with polycystic ovary syndrome: a systematic review and meta-analysis. Fertility and Sterility $2019 \mathbf{1 1 1}$ 168-177. (https://doi.org/10.1016/j.fertnstert.2018.09.013)

14 Lim SS, Norman RJ, Davies MJ \& Moran LJ. The effect of obesity on polycystic ovary syndrome: a systematic review and meta-analysis. Obesity Reviews 201314 95-109. (https://doi.org/10.1111/j.1467789X.2012.01053.x)

15 Jacewicz-Swiecka M \& Kowalska I. Polycystic ovary syndrome and the risk of cardiometabolic complications in longitudinal studies. Diabetes/Metabolism Research and Reviews 201834 e3054. (https://doi. org/10.1002/dmrr.3054)

16 Sundstrom P, Mellembakken JR, Papunen LM, Piltonen T, Puurunen J, Tapanainen JS, Stener-Victorin E, Hirschberg AL, Vanky E, Ravn P, et al. Should we individualize lipid profiling in women with polycystic ovary syndrome? Human Reproduction 201632966.

17 Pinola P, Puukka K, Piltonen TT, Puurunen J, Vanky E, SundströmPoromaa I, Stener-Victorin E, Lindén Hirschberg A, Ravn P, Skovsager Andersen M, et al. Normo- and hyperandrogenic women with polycystic ovary syndrome exhibit an adverse metabolic profile through life. Fertility and Sterility 2017 107 788.e2-795.e2. (https:// doi.org/10.1016/j.fertnstert.2016.12.017)
18 Jialal I. A practical approach to the laboratory diagnosis of dyslipidemia. American Journal of Clinical Pathology 1996106 128-138. (https://doi.org/10.1093/ajcp/106.1.128)

19 Glintborg D, Altinok M, Mumm H, Buch K, Ravn P \& Andersen M. Prolactin is associated with metabolic risk and cortisol in 1007 women with polycystic ovary syndrome. Human Reproduction 2014 29 1773-1779. (https://doi.org/10.1093/humrep/deu133)

20 Whelton PK, Carey RM, Aronow WS, Casey Jr DE, Collins KJ, Dennison Himmelfarb C, DePalma SM, Gidding S, Jamerson KA, Jones DW, et al. ACC/AHA/AAPA/ABC/ACPM/AGS/APhA/ASH/ASPC/ NMA/PCNA guideline for the prevention, detection, evaluation, and management of high blood pressure in adults: executive summary: a report of the American College of Cardiology/American Heart Association Task Force on Clinical Practice guidelines. Circulation 2018138 e426-e483.

21 Sesso HD, Stampfer MJ, Rosner B, Hennekens CH, Gaziano JM, Manson JE \& Glynn RJ. Systolic and diastolic blood pressure, pulse pressure, and mean arterial pressure as predictors of cardiovascular disease risk in men. Hypertension 200036 801-807. (https://doi. org/10.1161/01.hyp.36.5.801)

22 Williams B, Mancia G, Spiering W, Agabiti Rosei E, Azizi M, Burnier M, Clement D, Coca A, De Simone G, Dominiczak A, et al. 2018 Practice guidelines for the management of arterial hypertension of the European Society of Cardiology and the European Society of Hypertension. Blood Pressure 201827 314-340. (https://doi.org/10.10 80/08037051.2018.1527177)

23 Holte J, Gennarelli G, Berne C, Bergh T \& Lithell H. Elevated ambulatory day-time blood pressure in women with polycystic ovary syndrome: a sign of a pre-hypertensive state? Human Reproduction 1996 11 23-28. (https://doi.org/10.1093/oxfordjournals.humrep.a019028)

24 Zachurzok-Buczynska A, Szydlowski L, Gawlik A, Wilk K \& Malecka-Tendera E. Blood pressure regulation and resting heart rate abnormalities in adolescent girls with polycystic ovary syndrome. Fertility and Sterility 201196 1519-1525. (https://doi.org/10.1016/j. fertnstert.2011.09.043)

25 Bahri Khomami M, Ramezani Tehrani F, Hashemi S, Mohammadi N, Rashidi H \& Azizi F. Does the risk of metabolic disorders increase among women with polycystic ovary morphology? A populationbased study. Human Reproduction 201631 1339-1346. (https://doi. org/10.1093/humrep/dew071)

26 Joham AE, Boyle JA, Zoungas S \& Teede HJ. Hypertension in reproductive-aged women with polycystic ovary syndrome and association with obesity. American Journal of Hypertension 201528 847-851. (https://doi.org/10.1093/ajh/hpu251)

27 Cheung LP, Ma RC, Lam PM, Lok IH, Haines CJ, So WY, Tong PC, Cockram CS, Chow CC \& Goggins WB. Cardiovascular risks and metabolic syndrome in Hong Kong Chinese women with polycystic ovary syndrome. Human Reproduction 200823 1431-1438. (https:// doi.org/10.1093/humrep/den090)

28 Luque-Ramirez M, Marti D, Fernandez-Duran E, Alpanes M, AlvarezBlasco F \& Escobar-Morreale HF. Office blood pressure, ambulatory blood pressure monitoring, and echocardiographic abnormalities in women with polycystic ovary syndrome: role of obesity and androgen excess. Hypertension 201463 624-629. (https://doi. org/10.1161/HYPERTENSIONAHA.113.02468)

29 Lewington S, Clarke R, Qizilbash N, Peto R, Collins R \& Prospective Studies Collaboration. Age-specific relevance of usual blood pressure to vascular mortality: a meta-analysis of individual data for one million adults in 61 prospective studies. Lancet $20023601903-1913$. (https://doi.org/10.1016/s0140-6736(02)11911-8)

30 Rapsomaniki E, Timmis A, George J, Pujades-Rodriguez M, Shah AD, Denaxas S, White IR, Caulfield MJ, Deanfield JE, Smeeth L, et al. Blood pressure and incidence of twelve cardiovascular diseases: lifetime risks, healthy life-years lost, and age-specific associations in 1.25 million people. Lancet 2014383 1899-1911. (https://doi. org/10.1016/S0140-6736(14)60685-1)

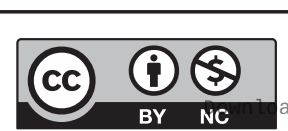

This work is licensed under a Creative Commons Attribution-NonCommercial 4.0 International License. ded from Bioscientifica.com at 04/26/2023 06:38:40Am 
31 Huang Z, Willett WC, Manson JE, Rosner B, Stampfer MJ, Speizer FE \& Colditz GA. Body weight, weight change, and risk for hypertension in women. Annals of Internal Medicine 1998128 81-88. (https://doi.org/10.7326/0003-4819-128-2-199801150-00001)

32 Yi SW, Yi JJ \& Ohrr H. Total cholesterol and all-cause mortality by sex and age: a prospective cohort study among 12.8 million adults. Scientific Reports 201991596.

33 Li FR, Zhang XR, Zhong WF, Li ZH, Gao X, Kraus VB, Lv YB, Zou MC, Chen GC, Chen PL, et al. Glycated hemoglobin and all-cause and cause-specific mortality among adults with and without diabetes. Journal of Clinical Endocrinology and Metabolism 2019104 3345-3354. (https://doi.org/10.1210/jc.2018-02536)

34 Khaw KT, Wareham N, Bingham S, Luben R, Welch A \& Day N. Association of hemoglobin A1c with cardiovascular disease and mortality in adults: the European prospective investigation into cancer in Norfolk. Annals of Internal Medicine 2004141 413-420. (https://doi.org/10.7326/0003-4819-141-6-200409210-00006)

35 Yi SW, Park S, Lee YH, Park HJ, Balkau B \& Yi JJ. Association between fasting glucose and all-cause mortality according to sex and age: a prospective cohort study. Scientific Reports 201778194
36 Mioni R, Cà AD, Turra J, Azzolini S, Xamin N, Bleve L, Maffei P, Vettor R \& Fallo F. Hyperinsulinemia and obese phenotype differently influence blood pressure in young normotensive patients with polycystic ovary syndrome. Endocrine 201755 625-34.

37 Kahal H, Kyrou I, Uthman OA, Brown A, Johnson S, Wall PDH, Metcalfe A, Parr DG, Tahrani AA \& Randeva HS. The prevalence of obstructive sleep apnoea in women with polycystic ovary syndrome: a systematic review and meta-analysis. Sleep and Breathing 202024 339-350. (https://doi.org/10.1007/s11325-019-01835-1)

38 Pinola P, Piltonen TT, Puurunen J, Vanky E, Sundstrom-Poromaa I, Stener-Victorin E, Ruokonen A, Puukka K, Tapanainen JS \& Morin-Papunen LC. Androgen profile through life in women with polycystic ovary syndrome: a Nordic multicenter collaboration study. Journal of Clinical Endocrinology and Metabolism 2015100 3400-3407. (https://doi.org/10.1210/jc.2015-2123)

39 Glintborg D, Mumm H, Ravn P \& Andersen M. Age associated differences in prevalence of individual Rotterdam criteria and metabolic risk factors during reproductive age in 446 Caucasian women with polycystic ovary syndrome. Hormone and Metabolic Research 201244 694-698. (https://doi.org/10.1055/s-0032-1304608)

Received in final form 29 October 2020

Accepted 5 January 2021

Accepted Manuscript published online 9 January 2021 https://ec.bioscientifica.com https://doi.org/10.1530/EC-20-0527 (c) 2021 The authors Published by Bioscientifica Ltd
This work is licensed under a Creative Commons Attribution-NonCommercial 4.0 International License. ded from Bioscientifica.com at 04/26/2023 06:38:40AM via free access 